\title{
Avaliação do desempenho estrutural em serviço de lajes treliçadas pré- moldadas de concretos com agregados leves
}

Evaluation of the structural performance at service of concrete precast truss slabs with lightweight aggregates

\section{Anderson de Oliveira \\ Sergio Luis González Garcia Guilherme Chagas Cordeiro}

\section{Resumo}

Anderson de Oliveira Laboratório de Engenharia Civil Universidade Estadual do Norte Fluminense Darcy Ribeiro Av. Alberto Lamego, 2000, Parque Califórnia Campos dos Goytacazes - RJ - Brasil CEP 28013-602 Tel. (22) 2739-7381

eng_civil_anderson@hotmail.com

Sergio Luis González Garcia Laboratório de Engenharia Civil Universidade Estadual do Norte Fluminense Darcy Ribeiro E-mail: liluiser@uenf.br

Guilherme Chagas Cordeiro Laboratório de Engenharia Civil Universidade Estadual do Norte Fluminense Darcy Ribeiro E-mail: gcc@uenf.br

Recebido em 19/01/11 Aceito em 05/12/11

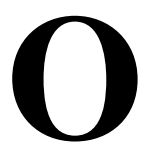

concreto com agregado leve tem sido cada vez mais empregado em razão da reduzida massa específica, do elevado isolamento térmico e acústico e da melhoria na resistência estrutural a carregamentos cíclicos. Neste trabalho foram estudados concretos com agregados leves com resistência à compressão em torno de $20 \mathrm{MPa}$ e seu desempenho estrutural em lajes treliçadas pré-moldadas. Utilizaram-se três diferentes concretos com valores de massa específica entre 1.200 e $1.600 \mathrm{~kg} / \mathrm{m}^{3}$. Os concretos foram avaliados com relação à resistência à compressão (aos 3, 7 e 28 dias) e à absorção total de água (aos 28 dias). Com os três tipos de concreto foram produzidas e ensaiadas à flexão lajes pré-moldadas (duas lajes para cada tipo de concreto), com a avaliação de seu comportamento no estado limite de serviço (ELS) para cargas de curta duração, ou seja, sem considerar efeitos ao longo do tempo. Os resultados mostraram o potencial do uso de concretos com agregados leves nesse tipo de laje estrutural.

Palavras-chave: Concreto com agregado leve. Argila expandida. Lajes pré-moldadas. Estado limite de serviço.

\section{Abstract}

Lightweight aggregate concrete has been widely used due to its low density, high thermal and acoustic insulation properties, and also due to its improved structural strength under cyclic loading. In this study, concretes containing lightweight aggregates of compressive strength about $20 \mathrm{MPa}$ were studied and its use in precast truss slabs was evaluated. Three different concretes with density values between 1,200 and $1,600 \mathrm{~kg} / \mathrm{m}^{3}$ were investigated. The concretes were evaluated taking as basis the compressive strength (at 3, 7 and 28 days) and the total water absorption (at 28 days). Using the three types of concrete, precast slabs were produced and tested under bending (two slabs for each type of concrete) and their behavior at the serviceability limit state (SLS) for short-term loading was evaluated, without considering time-dependent effects. The results showed the potential of using lightweight aggregate concretes in this type of structural slab.

Keywords: Lightweight aggregate concrete. Expanded clay. Precast slabs. Serviceability limit state. 


\section{Introdução}

O concreto estrutural leve é definido pelo American Concrete Institute (AMERICAN..., 2003) como um concreto com resistência à compressão aos 28 dias acima de $17 \mathrm{MPa}$, e massa específica aos 28 dias, seca ao ar, não superior a $1.850 \mathrm{~kg} / \mathrm{cm}^{3}$. O concreto estrutural com agregados leves apresenta-se atualmente como um material com aplicação em diversas áreas da construção civil devido aos benefícios promovidos pela redução da massa específica. Essa característica proporciona redução dos esforços nas estruturas e fundações (GAO; SUN; MORINO, 1997) e dos custos com transporte e montagem quando utilizado em construções pré-fabricadas (ROSSIGNOLO, 2005). A redução da massa da estrutura também é muito interessante para a prevenção de riscos estruturais devido a ações dinâmicas, como terremotos (YASAR et al., 2003), por exemplo.

O estudo das propriedades físicas e mecânicas dos concretos com agregados leves tem aumentado nos últimos anos devido a vantagens técnicas em relação aos concretos com agregados convencionais (ROSSIGNOLO; AGNESINI; MORAIS, 2003; CHEN; LIU, 2005, 2008; LO; TANG; CUI, 2007; LOPEZ; KAHN; KURTIS, 2008; LIU; CHIA; ZHANG, 2011; SHANNAG, 2011). Além disso, o emprego de argila expandida como agregado pode reduzir significativamente as deformações de fluência e retração do concreto. Segundo Lopez, Kahn e Kurtis (2008), a água contida no interior do agregado leve contribui para aumentar o grau de hidratação do cimento Portland e manter a umidade relativa interna alta, o que reduz a retração autógena.

Este trabalho apresenta resultados de lajes prémoldadas com três diferentes concretos leves que foram avaliadas no estado limite de serviço (ELS).
Os concretos com valores de massa específica entre 1.200 e $1.600 \mathrm{~kg} / \mathrm{m}^{3}$ foram avaliados com relação à resistência à compressão (aos 3,7 e 28 dias) e à absorção total de água (aos 28 dias). É importante ressaltar que outros ensaios devem ainda ser realizados para avaliar a viabilidade desse sistema estrutural. Nesse escopo, o desempenho estrutural das lajes no estado limite último (ELU) e ensaios estruturais de longa duração serão apresentados em futuras publicações.

\section{Materiais e métodos}

Para a produção dos concretos leves foram utilizados os seguintes materiais: cimento Portland CP II F 32, argila expandida com tamanho máximo de $16 \mathrm{~mm}$, areia quartzosa natural e argila expandida com tamanho máximo de $4,8 \mathrm{~mm}$. A Tabela 1 apresenta as características físicas dos agregados utilizados.

Os três diferentes concretos foram dosados com base no método ACI 211.2 (AMERICAN..., 1998) para uma resistência à compressão de $20 \mathrm{MPa}$ aos 28 dias. Os três concretos foram confeccionados com argila expandida (argila 2) como agregado graúdo. O primeiro concreto, denominado C100A, foi produzido com $100 \%$ de agregado miúdo convencional (areia quartzosa). No segundo concreto (C50L) foram utilizados $50 \%$ de agregado miúdo de areia quartzosa e $50 \%$ restantes de agregado miúdo leve (argila expandida 1). O terceiro concreto $(\mathrm{C} 100 \mathrm{~L})$, por sua vez, foi produzido com $100 \%$ de agregado miúdo leve. Uma relação água-cimento igual a 0,48 foi utilizada em todos os concretos. A Tabela 2 apresenta as quantidades (em massa) de materiais consumidos por metro cúbico nos diferentes concretos.

Tabela 1 - Características físicas dos agregados

\begin{tabular}{l|c|c|c}
\hline \multirow{2}{*}{ Características } & \multicolumn{2}{|c|}{ Agregados miúdos } & Agregado graúdo \\
\cline { 2 - 4 } & Areia natural & Argila expandida 1 & Argila expandida 2 \\
\hline Tamanho máximo & $4,8 \mathrm{~mm}$ & $4,8 \mathrm{~mm}$ & $16 \mathrm{~mm}$ \\
Módulo de finura & 2,24 & 3,63 & 6,77 \\
Massa específica & $2.574 \mathrm{~kg} / \mathrm{m}^{3}$ & $1.930 \mathrm{~kg} / \mathrm{m}^{3}$ & $1.100 \mathrm{~kg} / \mathrm{m}^{3}$ \\
Massa unitária & $1.425 \mathrm{~kg} / \mathrm{m}^{3}$ & $829 \mathrm{~kg} / \mathrm{m}^{3}$ & $692 \mathrm{~kg} / \mathrm{m}^{3}$ \\
\hline
\end{tabular}

38 Oliveira, A. de; Garcia, S. L. G.; Cordeiro, G. C. 
Tabela 2 - Consumo de material em quilograma por metro cúbico de concreto

\begin{tabular}{l|c|c|c}
\hline \multirow{2}{*}{\multicolumn{1}{c}{ Materiais }} & \multicolumn{3}{|c}{ Concretos } \\
\cline { 2 - 4 } & C100A & C50L & C100L \\
\hline Cimento Portland & 380,3 & 380,3 & 380,3 \\
Argila expandida 2 & 474,7 & 474,7 & 474,7 \\
Areia quartzosa & 663,4 & 331,7 & - \\
Argila expandida 1 & - & 193,0 & 385,9 \\
Água & 220,0 & 220,0 & 220,0 \\
\hline
\end{tabular}

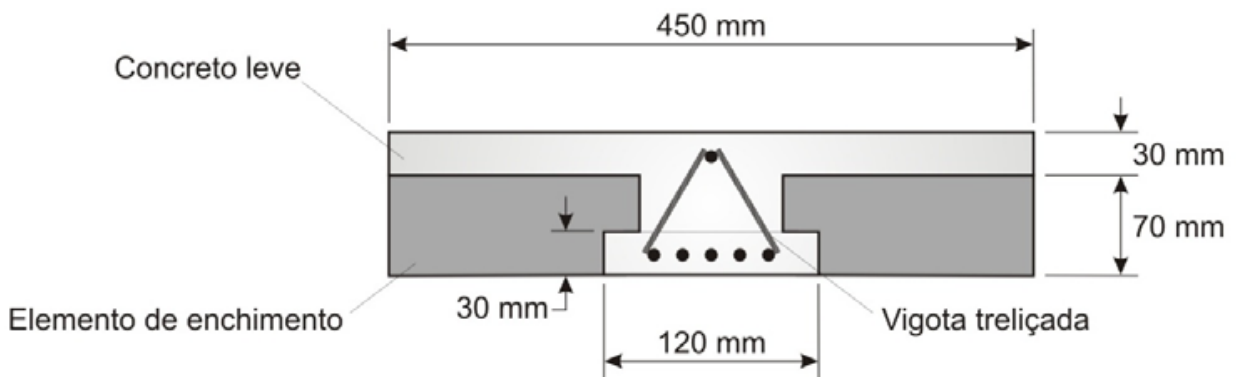

Figura 1 - Seção transversal das lajes estudadas

Os concretos foram produzidos em betoneira de eixo inclinado de laboratório. A ordem de mistura dos constituintes foi a seguinte: mistura dos agregados leves por 1 min; adição de $70 \%$ da água e repouso por 10 min; adição de cimento e mistura por $1 \mathrm{~min}$; acréscimo do agregado convencional (no caso dos concretos C100A e C50L) e do restante da água e mistura final por $3 \mathrm{~min}$. A moldagem e a cura dos corpos de prova foram executadas conforme procedimentos recomendados pela NBR 5738 (ABNT, 2003a). A resistência à compressão dos concretos foi avaliada após 3, 7 e 28 dias de cura por imersão, por meio de ruptura de corpos de prova cilíndricos $(100 \mathrm{~mm}$ de diâmetro e $200 \mathrm{~mm}$ de altura) em máquina universal de ensaios Shimadzu UH-F1000kNI. Os ensaios foram conduzidos de acordo com a NBR 5739 (ABNT, 2007), com velocidade de carregamento de $0,025 \mathrm{~mm} / \mathrm{min}$. A deformação dos concretos foi calculada a partir dos valores de deslocamento obtidos com transdutores elétricos de deslocamento. A partir dos dados de tensão e deformação foi calculado o módulo de elasticidade secante de acordo com a Equação 1. Foram realizados 3 ensaios por idade e tipo de concreto.

$\mathrm{E}=\left(\sigma_{2}-\sigma_{1}\right) \cdot\left(\varepsilon_{2}-\varepsilon_{1}\right)^{-1}$

Eq. 1

Sendo:

E o módulo de elasticidade;

$\sigma_{2}$ a tensão correspondente à deformação $5 \cdot 10^{-5}$;

$\sigma_{1}$ a tensão correspondente a $30 \%$ da tensão máxima;

$\varepsilon_{2}$ a deformação de $5.10^{-5}$; e

$\varepsilon_{1}$ a deformação correspondente a $\sigma_{1}$.
Após 28 dias de cura, a massa específica e a absorção de água foram determinadas de acordo com os procedimentos descritos na NBR 9778 (ABNT, 2009). Após a caracterização dos concretos, seis lajes treliçadas pré-moldadas (ABNT, 2002) foram produzidas em laboratório (duas com cada tipo de concreto). Para a produção das lajes foram utilizadas treliças metálicas Gerdau TR 08644 (GERDAU, 2010). Além da treliça foram acrescentadas 3 barras de aço CA-60 de 5 mm de diâmetro como armadura longitudinal de tração adicional. $\mathrm{O}$ elemento de enchimento foi de poliestireno expandido com $165 \mathrm{~mm}$ de largura, 70 $\mathrm{mm}$ de altura e $1.000 \mathrm{~mm}$ de comprimento. As vigotas treliçadas com $30 \mathrm{~mm}$ de altura, $120 \mathrm{~mm}$ de largura e $2.100 \mathrm{~mm}$ de comprimento foram previamente produzidas com o mesmo concreto utilizado no restante da laje. As lajes foram produzidas com $450 \mathrm{~mm}$ de largura, $100 \mathrm{~mm}$ de altura e $2.100 \mathrm{~mm}$ de comprimento, e a Figura 1 mostra sua seção transversal.

As lajes foram instrumentadas com extensômetros elétricos de resistência (strain-gages) unidirecionais posicionados na armadura longitudinal tracionada e na borda mais comprimida do concreto. Durante os ensaios das lajes, os deslocamentos no meio do vão foram medidos com transdutores elétricos de deslocamento. O carregamento foi aplicado utilizando-se um sistema com um reservatório com entrada de água com vazão controlada por uma bomba hidráulica, conforme ilustra a Figura 2. O carregamento foi aplicado, desta forma, em cerca de $0,1 \mathrm{kN} / \mathrm{min}$. O reservatório foi acoplado ao 
sistema de aplicação de carga por meio de duas células de carga com capacidade de leitura de 50 $\mathrm{kN}$. O carregamento foi transmitido por meio de um perfil metálico de distribuição dos esforços no terço central das lajes. Os valores de força, deformação e deslocamento foram gravados usando-se o sistema de aquisição ADS 2000 da Lynx.

Os valores de flechas teóricas imediatas foram calculados para as três diferentes lajes de acordo com as Equações 2 e 3, conforme procedimentos descritos na NBR 6118 (ABNT, 2003b). As flechas teóricas foram calculadas para uma carga de serviço de $3,18 \mathrm{kN}$, valor determinado considerando $60 \%$ da carga teórica de flexão (valor aproximado para todas as lajes de $5,3 \mathrm{kN}$ ) e o módulo de elasticidade de cada uma das lajes estudadas.

$(E I)_{e q}=E_{c s}\left\{\left(\frac{M_{r}}{M_{a}}\right)^{3} I_{c}+\left[1-\left(\frac{M_{r}}{M_{a}}\right)^{3}\right] I_{I I}\right\} \leq E_{c s} I_{c} \quad$ Eq. 2

Sendo:

$I_{C}$ momento de inércia da seção bruta de concreto;

$I_{I I}$ momento de inércia da seção fissurada de concreto no estádio II;

$M_{a}$ momento fletor na seção crítica;

$E_{c S}$ módulo de elasticidade; e

$M_{r}$ momento de fissuração, que foi calculado pela Equação 3.

$\mathrm{M}_{\mathrm{r}}=\frac{\mathrm{f}_{\mathrm{ct}, \mathrm{f}} \cdot \mathrm{I}_{\mathrm{c}}}{\mathrm{y}_{\mathrm{t}}}$
Sendo:

$f_{c t, f}$ a resistência média à tração na flexão do concreto; e

$y_{t}$ a distância do centro de gravidade da seção à fibra mais tracionada.

A previsão da flecha imediata ou instantânea foi feita a partir da Equação 4, considerando o $E I_{e q}$ (Equação 2).

$\mathrm{f}=\frac{M_{a}\left(3 L^{2}-4 a^{2}\right)}{24 \mathrm{EI}_{\mathrm{eq}}}$

Sendo:

f a flecha teórica;

$L$ o vão (2.000 mm); e

$a$ o vão de cisalhamento $(800 \mathrm{~mm})$.

\section{Resultados e discussões}

\section{Caracterização dos concretos leves}

Os valores de absorção de água e massa específica dos três concretos estudados estão indicados na Tabela 3. É possível observar que os valores de massa específica foram expressivamente inferiores aos típicos para um concreto convencional (em torno de $2.400 \mathrm{~kg} / \mathrm{m}^{3}$ ). Como esperado, quanto maior o conteúdo de agregado leve na mistura, menor o valor de massa específica. Os concretos com agregados miúdos leves apresentaram maiores valores médios de absorção de água. Esse fato é decorrente da elevada porosidade da argila expandida.

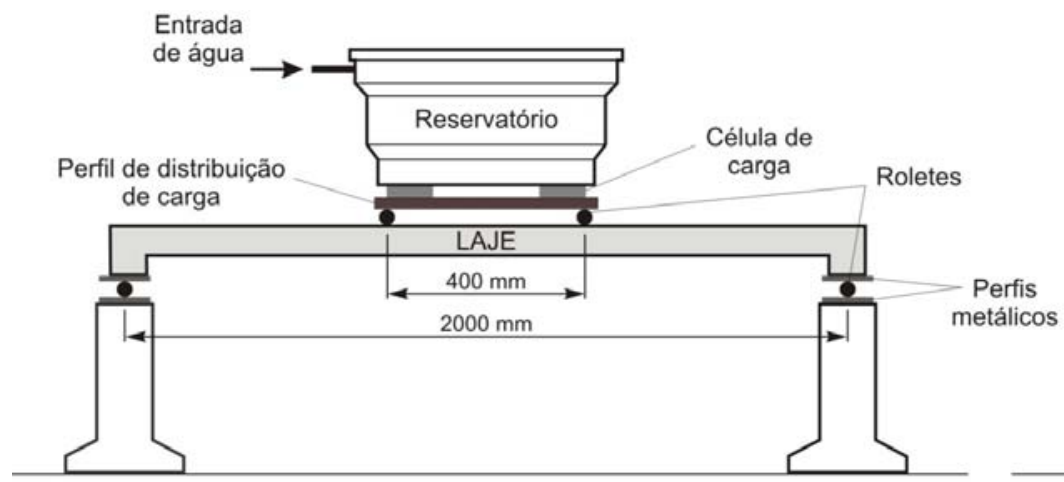

(a)

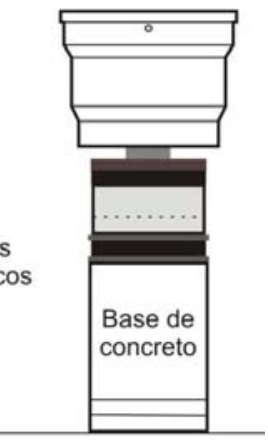

(b)

Figura 2 - Esquema de aplicação de carga nos ensaios das lajes: (a) vista frontal; (b) vista lateral esquerda 
Tabela 3 - Valores de adsorção de água e massa específica dos concretos

\begin{tabular}{c|c|c}
\hline Concretos & Absorção de água (\%) & Massa específica (kg/m $\left.\mathbf{m}^{3}\right)$ \\
\hline C100A & 7,8 & 1.547 \\
C50L & 9,4 & 1.442 \\
C100L & 10,6 & 1.267 \\
\hline
\end{tabular}

Tabela 4 - Propriedades mecânicas dos concretos estudados (os valores entre parênteses referem-se aos desvios padrão)

\begin{tabular}{c|c|c|c}
\hline \multicolumn{4}{c}{ Resistência à compressão (MPa) } \\
\hline Concretos & 3 dias & $\mathbf{7}$ dias & $\mathbf{2 8}$ dias \\
C100L & $14,9( \pm 0,71)$ & $17,6( \pm 2,25)$ & $21,1( \pm 0,35)$ \\
C50L & $18,5( \pm 1,08)$ & $20,5( \pm 0,83)$ & $22,4( \pm 1,50)$ \\
C100A & $12,0( \pm 0,17)$ & $15,6( \pm 0,28)$ & $17,7( \pm 1,59)$ \\
\hline \multicolumn{4}{c}{ Módulo de elasticidade (GPa) } \\
\hline C100L & $11,7( \pm 0,08)$ & $12,4( \pm 1,06)$ & $14,2( \pm 0,54)$ \\
C50L & $13,9( \pm 0,08)$ & $14,9( \pm 0,83)$ & $16,1( \pm 1,80)$ \\
C100A & $13,6( \pm 0,17)$ & $13,8( \pm 0,28)$ & $15,5( \pm 1,29)$ \\
\hline
\end{tabular}

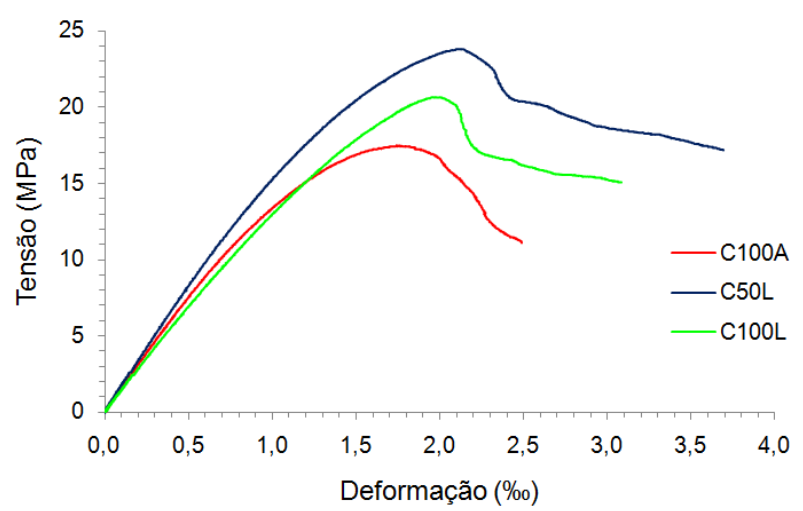

Figura 3 - Curvas típicas tensão versus deformação dos concretos leves estruturais aos 28 dias

A Tabela 4 mostra os valores de resistência à compressão e de módulo de elasticidade dos concretos estudados. Nota-se que após 3 dias de cura todos os concretos apresentaram diferenças significativas de acordo com Análise de Variância ao nível de significância de 0,05 . A resistência à compressão do concreto C50L foi cerca de $25 \%$ e $55 \%$ superior às resistências dos concretos $\mathrm{C} 100 \mathrm{~L}$ e C100A respectivamente. Aos 7 dias os concretos C100L e C100A não apresentaram diferenças significativas entre si no que se refere à resistência. A mistura C50L foi também mais resistente aos 7 dias. Após 28 dias de cura observa-se que os concretos C50L e C100L apresentam maiores resistências (não diferentes entre si) que o concreto C100A, apesar da maior absorção de água verificada nos concretos com agregado miúdo leve. Esse comportamento pode ser explicado pela melhoria na zona de transição entre os agregados leves e a pasta (LO; CUI, 2004) e pela maior disponibilidade de água para as reações de hidratação do cimento Portland (LOPEZ; KAHN; KURTIS, 2008). É importante ressaltar que a resistência de dosagem foi superada nos concretos C50L e C100L.

Com relação ao módulo de elasticidade, o comportamento dos concretos foi similar ao observado para a resistência à compressão. Os concretos C100L e C50L não apresentaram ganhos significativos de módulo de elasticidade entre as idades de 3 e 28 dias. Contudo, o concreto C100A apresentou valor de módulo superior aos demais em cerca de 13\%. Aos 28 dias, os concretos não apresentaram diferenças significativas nos módulos de elasticidade. É importante destacar que o baixo módulo de elasticidade, em comparação com concretos convencionais, é uma característica dos concretos leves estruturais. Essa característica é originada pela reduzida resistência mecânica dos agregados de argila expandida em comparação com agregados naturais rochosos. Os concretos estudados apresentaram valores de módulo de elasticidade abaixo de $16 \mathrm{GPa}$. O concreto $\mathrm{C} 100 \mathrm{~L}$ apresentou o menor valor de módulo entre os concretos estudados. A Figura 3 apresenta as 
curvas típicas tensão versus deformação dos concretos aos 28 dias, que atestam a maior resistência da mistura $\mathrm{C} 50 \mathrm{~L}$, e que os concretos atingiram deformações de pico em torno de $2 \%$.

\section{Análise das lajes}

A Tabela 5 apresenta os valores de flecha limite, teórica e experimental das lajes estudadas. As flechas teóricas foram obtidas a partir da Equação 4, e as flechas experimentais foram obtidas nos ensaios de flexão para uma carga de serviço de $3,18 \mathrm{kN}$, equivalente a $60 \%$ da carga teórica resistente à flexão. A flecha limite foi obtida segundo as prescrições da NBR 6118 (ABNT, 2003b), ou seja, L/250 (0,8 cm). Na Tabela 5 é possível observar, ainda, que os maiores valores de flechas teóricas e experimentais foram obtidos para o concreto com argila expandida como agregado graúdo e miúdo $(\mathrm{C} 100 \mathrm{~L})$. Além disso, nota-se que todas as flechas experimentais (com exceção da C100L - Laje 1) foram inferiores às flechas teóricas, e quatro lajes apresentaram flechas experimentais superiores ao limite estabelecido pela NBR 6118 (ABNT, 2003b). Com base na dosagem utilizada nesta pesquisa, o emprego de concreto contendo 100\% de agregado leve (graúdo e miúdo) não atendeu à exigência de flecha limite estabelecida pela NBR 6118.

A Figura 4 mostra as curvas carga versus deslocamento no meio do vão (flecha imediata) para cada uma das lajes estudadas, assim como o valor limite de flecha segundo a NBR 6118 (ABNT, 2003b). Nota-se que as duas lajes confeccionadas com $\mathrm{C} 100 \mathrm{~L}$ apresentaram maiores flechas, corroborando o menor módulo de elasticidade evidenciado para esse tipo de concreto (Tabela 4). O deslocamento inicial das curvas refere-se à flecha teórica devida ao peso próprio das lajes acrescido do peso próprio do aparato de aplicação de carga utilizado.

A Figura 5 mostra as curvas carga versus deformação dos concretos na borda mais comprimida das lajes. Os concretos atingiram deformações abaixo de $0,5 \%$ em todos os casos para a carga de serviço adotada $(3,18 \mathrm{kN})$. Além disso, observa-se que uma das lajes C100L (ensaio 2) apresentou a maior deformação do concreto entre todas as lajes ensaiadas. Esse fato certamente contribuiu para a ocorrência da maior flecha visualizada na Figura 4. Fissuras visíveis não foram detectadas nas lajes até o nível de carga adotado neste trabalho.

Tabela 5 - Valores de flechas limite, teóricas e experimentais das lajes ensaiadas

\begin{tabular}{cl|c|c|c|c}
\hline \multicolumn{2}{c|}{ Lajes } & $\begin{array}{c}\text { Flecha } \\
\text { limite } \\
\text { (mm) }\end{array}$ & $\begin{array}{c}\text { Flecha } \\
\text { teórica } \\
\mathbf{( m m}\end{array}$ & $\begin{array}{c}\text { Flecha } \\
\text { experimental } \\
\text { (mm) }\end{array}$ & $\begin{array}{c}\text { Flecha } \\
\text { experimental/Flecha } \\
\text { teórica }\end{array}$ \\
\hline \multirow{2}{*}{ C100L } & Laje 1 & & 9,49 & 9,95 & 1,05 \\
& Laje 2 & & 9,49 & 9,26 & 0,98 \\
\multirow{2}{*}{ C50L } & Laje 1 & \multirow{2}{*}{8,0} & 9,28 & 7,73 & 0,83 \\
& Laje 2 & & 9,28 & 7,30 & 0,79 \\
\multirow{2}{*}{$\mathrm{C} 100 \mathrm{~A}$} & Laje 1 & & 9,37 & 7,90 & 0,84 \\
& Laje 2 & & 9,37 & 7,18 & 0,77 \\
\hline
\end{tabular}

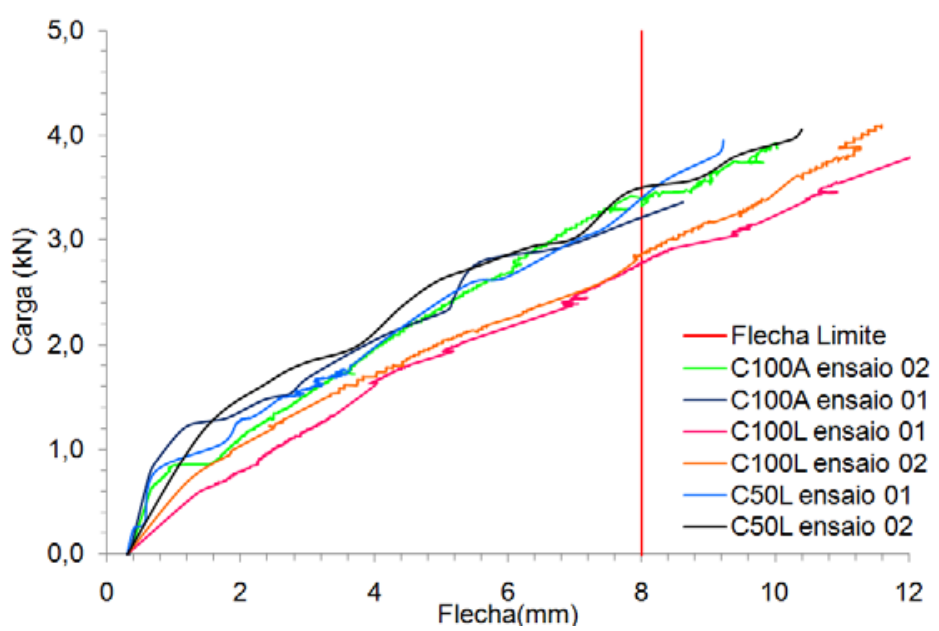

Figura 4 - Curvas carga versus deslocamento no meio do vão (flecha) para as lajes estudadas 


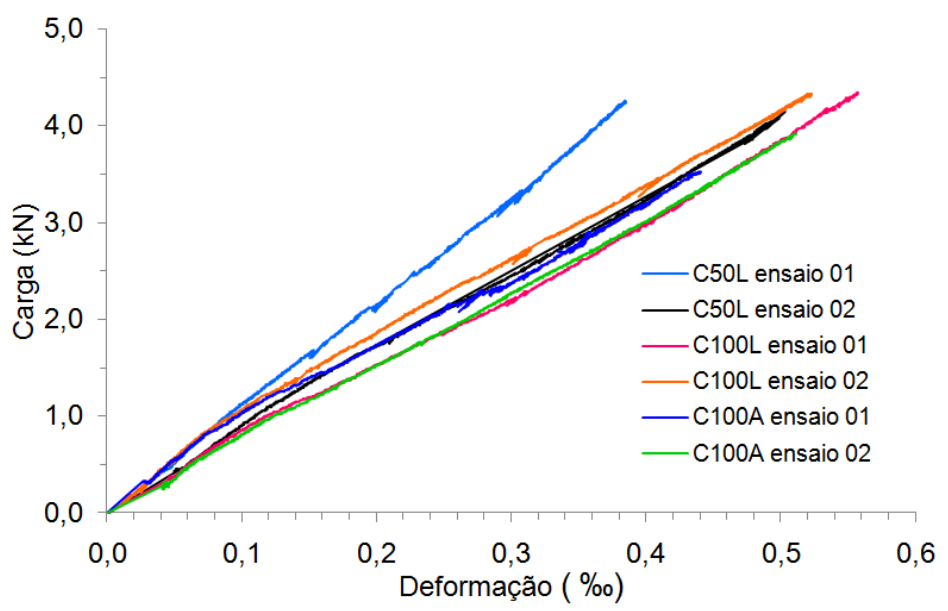

Figura 5 - Curvas carga versus deformação do concreto na borda mais comprimida das lajes

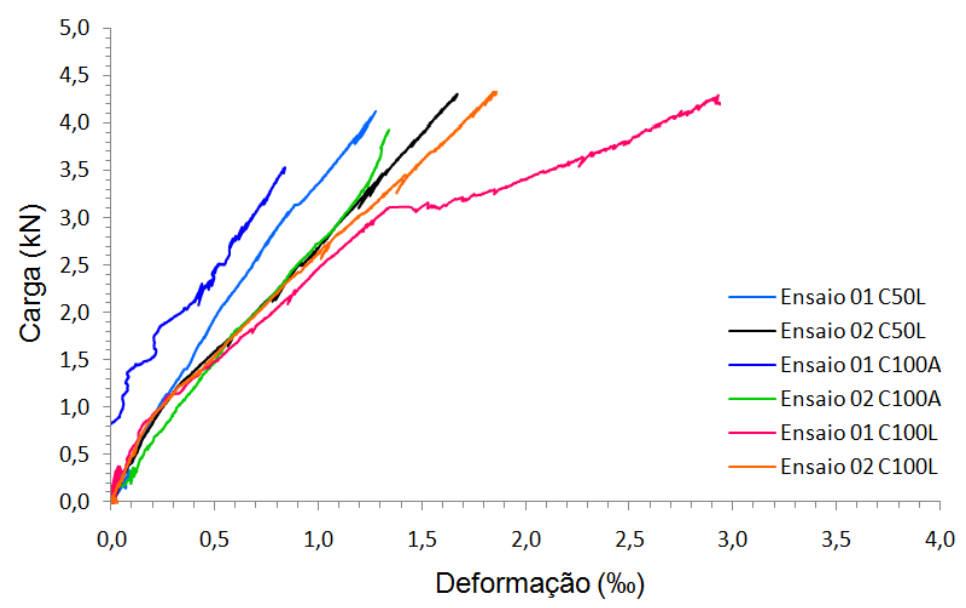

Figura 6 - Curvas carga versus deformação da armadura longitudinal de tração das lajes estudadas

Tabela 6 - Deformação do concreto na borda mais comprimida e da armadura longitudinal de tração para as cargas experimentais

\begin{tabular}{cc|c|c|c}
\hline \multicolumn{2}{c|}{ Lajes } & $\begin{array}{c}\text { Carga } \\
\text { experimental } \\
\mathbf{( k N )}\end{array}$ & $\begin{array}{c}\text { Deformação do } \\
\text { concreto (\%o) }\end{array}$ & $\begin{array}{c}\text { Deformação do } \\
\text { aço (\%o) }\end{array}$ \\
\hline \multirow{2}{*}{ C100L } & Laje 1 & & 0,44 & 1,35 \\
\multirow{2}{*}{ C50L } & Laje 2 & \multirow{2}{*}{3,18} & 0,38 & 1,26 \\
& Laje 1 & & 0,31 & 0,88 \\
\multirow{2}{*}{ C100A } & Laje 2 & & 0,40 & 1,18 \\
& Laje 1 & & 0,41 & 0,72 \\
\hline
\end{tabular}

As curvas carga versus deformação na armadura longitudinal de tração das lajes estudadas estão apresentadas na Figura 6. As armaduras de aço apresentaram um nível de deformação em concordância com o nível de carga aplicada em cada laje. A Tabela 6 mostra a deformação do concreto na borda mais comprimida e da armadura longitudinal de tração para a carga de serviço de $3,18 \mathrm{kN}$. É importante destacar que para o nível de carga adotado, variações expressivas nos valores de deformação do concreto não foram observadas em decorrência dos diferentes valores de módulo de elasticidade dos concretos. Entretanto, as maiores deformações na armadura foram observadas nas lajes confeccionadas com $\mathrm{o}$ concreto C100L, que apresentou menor módulo de elasticidade. 


\section{Conclusões}

Com base nos estudos realizados pode-se concluir que:

(a) foi possível a produção de concretos com baixa resistência à compressão para uso em lajes pré-moldadas estruturais com emprego de argila expandida em substituição parcial dos agregados convencionais;

(b) os concretos estudados atingiram deformação de pico em torno de $2 \%$, variando em função do tipo de agregado utilizado; e

(c) pela avaliação do comportamento no estado limite de serviço, observou-se que as lajes confeccionadas com $100 \%$ dos agregados leves (C100L) apresentaram maiores flechas imediatas em decorrência do menor módulo de elasticidade apresentado por esse tipo de concreto. Fissuras não foram observadas.

Com isso, pode-se concluir que os concretos com agregados graúdos leves estudados apresentam grande potencial de uso em lajes pré-moldadas por associar o desempenho mecânico satisfatório com a reduzida massa específica. Contudo, outros estudos são necessários para investigar o efeito de carregamentos de longo prazo, de carregamentos dinâmicos e da resistência à flexão e à punção no estado limite último. Além disso, ressalta-se que o emprego de agregados leves, por reduzir o módulo de elasticidade, requer uma cuidadosa verificação do estado limite de deformações excessivas na laje.

\section{Referências bibliográficas}

AMERICAN CONCRETE INSTITUTE. ACI

211.2: standard practice for selecting proportions for structural lightweight concrete. Detroit, 1998.

AMERICAN CONCRETE INSTITUTE. ACI

213R-03: guide for structural lightweightaggregate concrete. Detroit, 2003.

ASSOCIAÇÃO BRASILEIRA DE NORMAS TÉCNICAS. NBR 5738: concreto: procedimento para moldagem e cura de corpos-de-prova. Rio de Janeiro, 2003a.

ASSOCIAÇÃO BRASILEIRA DE NORMAS TÉCNICAS. NBR 5739: concreto: ensaios de compressão de corpos-de-prova cilíndricos. Rio de Janeiro, 2007.

ASSOCIAÇÃO BRASILEIRA DE NORMAS TÉCNICAS. NBR 6118: projeto de estruturas de concreto: procedimento. Rio de Janeiro, 2003 b.
ASSOCIAÇÃO BRASILEIRA DE NORMAS TÉCNICAS. NBR 9778: argamassa e concreto endurecidos: determinação da absorção de água, índice de vazios e massa específica. Rio de Janeiro, 2009.

ASSOCIAÇÃO BRASILEIRA DE NORMAS TÉCNICAS. NBR 14859-1: laje pré-fabricada: requisitos: parte 1: lajes unidirecionais. Rio de Janeiro, 2002.

CHEN, B.; LIU, J. Contribution of Hybrid Fibers on the Properties of the High-Strength Lightweight Concrete Having Good Workability. Cement and Concrete Research, v. 35, n. 5, p. 913- 917, 2005.

CHEN, B.; LIU, J. Experimental Application of Mineral Admixtures in Lightweight Concrete With High Strength and Workability. Construction and Building Materials, v. 22, n. 4, p. 655-659, 2008.

GAO, J.; SUN, W.; MORINO, K. Mechanical Properties of Steel Fiber-Reinforced, HighStrength, Lightweight Concrete. Cement \& Concrete Composites, v. 19, n. 4, p. 307-313, 1997.

GERDAU. [Produtos e serviços]. Disponível em: $<$ http://www.gerdau.com.br/produtos-e-servicos/>. Acesso em: 5 dez. 2010.

LIU, X.; CHIA, K. S.; ZHANG, M.-H. Water Absorption, Permeability, and Resistance to Chloride-Ion Penetration of Lightweight Aggregate Concrete. Construction and Building Materials, v. 25, n. 1, p. 335-343, 2011.

LO, T. Y.; TANG, W.C.; CUI, H. Z. The Effects of Aggregate Properties on Lightweight Concrete. Building and Environment, v. 42, n. 8, p. 30253029, 2007.

LO, T. Y.; CUI, H. Z. Effects of Porous Aggregate on Strength of Concrete. Materials Letters, v. 58, n. 6, p. 916-919, 2004.

LOPEZ, M.; KAHN, L. F.; KURTIS, K. E. Effect of Internally Stored Water on Creep of HighPerformance Concrete. ACI Materials Journal, v. 105, n. 3, p. 303-311, 2008.

ROSSIGNOLO, J. A.; AGNESINI, M. V. C.; MORAIS, J. A. Properties of High-Performance LWAC for Precast Structures With Brazilian Lightweight Aggregates. Cement \& Concrete Composites, v. 253, n. 1, p. 77-82, 2003.

ROSSIGNOLO, J. A. Módulo de Deformação do Concreto Leve Estrutural de Alto Desempenho. Revista Minerva, São Paulo, SP, v. 2, n. 1, p. 99106, 2005. 
SHANNAG, M. J. Characteristics of Lightweight Concrete Containing Mineral Admixtures.

Construction and Building Materials, v. 25, n. 2, p. 658-662, 2011.

YASAR, E. et al. Strength Properties of Lightweight Concrete Made With Basaltic Pumice and Fly Ash. Materials Letters, v. 57, n. 15, p. 2267-2270, 2003.

\section{Agradecimentos}

À Faperj, pelo auxílio financeiro, e ao Laboratório de Estruturas e Materiais do Programa de Engenharia Civil da Coppe/UFRJ, onde os ensaios de compressão foram realizados.

Revista Ambiente Construído

Associação Nacional de Tecnologia do Ambiente Construído

Av. Osvaldo Aranha, 99 - 3o andar, Centro

Porto Alegre - RS - Brasil

CEP $90035-190$

Telefone: +55 (51) 3308-4084

Fax: +55 (51) 3308-4054

www. seer. ufrgs. br/ ambienteconstruido

E-mail: ambienteconstruido@ufrgs.br 